\title{
Perancangan Prototype Sistem Control Dan Monitoring Lahan Parkir Kendaraan Roda Dua Berbasis Arduino Mega 2560
}

\author{
Teguh Hidayat Iskandar Alam ${ }^{1}$, Rendra Soekarta ${ }^{2}$, Hasanuddinn ${ }^{3}$ \\ 1,2,3 Prodi Teknik Informatika, Universitas Muhammadiyah, Sorong \\ e-mail: ${ }^{1}$ teguhhidhayat@gmail.com, ${ }^{2}$ rendrasoekarta@gmail.com, ${ }^{3}$ hasanalfatih.um@gmail.com
}

\begin{abstract}
Abstrak
Peningkatan jumlah kendaraan di Universitas Muhhammadiyah Sorong berdampak pada lahan parkir yang mulai padat, peningktan ini dipengaruhi oleh peningkatan jumlah mahasiswa di Universitas Muhammadiyah Sorong. Hal ini akhirnya menyebabkan mahasiswa memarkirkan kendaraan mereka ke tempat yang tidak seharusnya dijadikan tempat parkir yang tentunya juga beresiko dari segi keamanan. Tujuan dari penelitian ini adalah untuk membuat sebuah sistem control dan monitoring lahan parkir agar pengendara memarkirkan kendaraan mereka dengnn tertib. Perancangan ini menggunakan Mikrokontroler Arduino mega 2560 yang merupakan pemgendali mikro single board dari keluarga Mikrokontroler ATmega[1], Motor Servo Sg 90 dan Sensor Infrared sebgai inputan untuk menggerakan Servo dan juga untuk menghitung kendaraan yang masuk dan keluar dari lahan parkir, jumlah kendaraan tersebut kemudian ditampilkan pada lcd (Liquid Crystal Display) serta Buzzer akan berbunyi sebagai notifikasi kepada pengendara apabila lahan parkir telah penuh.
\end{abstract}

Kata kunci : Monotoring Lahan Parkir, Parkir Otomatis, Menghitung kendaraan

\section{PENDAHULUAN}

$P$ enggunaan kendaraan pribadi dikalangan mahasiswa Universitas Muhamadiyah Sorong saat ini mengalami peningkatan yang tentunya berdampak pada lahan parkir yang mulai padat, akibatnya banyak mahasiswa yang terpaksa memarkirkan kendaraan mereka pada tempat-tempat yang seharusya tidak dijadikan tempat parkir, Selain itu ditinjau dari segi keamanan pola parkir yang tidak teratur membuat kendaraan rentan terhadap resiko pencurian dikarenakan Satpam sulit untuk memantau seluruh kendaraan yang parkir.

Oleh karena itu diperlukan sebuah sistem yang dapat mengatur proses parkir dengan baik di Universitas Muhammadiyah Sorong. Sistem yang dapat mengatur jumlah kendaraan yang dapat parkir pada tempat parkir yang disediakan agar tidak terjadi kepadatan, maupun sistem yang dapat memantau jumlah kendaraan yang parkir, serta notifikasi apabila lahan parkir yang disediakan telah penuh.

Sistem ini akan di bangun dengan menggunakan Board Arduino yang merupakan kit elektronik atau papan rangkaian elektronik open source yang di dalamnya terdapat komponen utama yaitu sebuah chip mikrokontroler dengan jenis AVR dari perusahaan Atmel [1]. yang dihubungkan dengan sensor infrared sebagai pendeteksi kendaraan yang akan keluar dan masuk pada area, sensor infrared ini merupakan komponen elekronika yang dapat mendeteksi cahaya infra merah (Infra-Red)[2], serta menggunakan LCD (liquid crystal display) yang akan menampilkan jumalah kendaraan yang berada pada lahan parkir, portal pada lahan akan di gerakan oleh Motor Servo pada pintu masuk dan keluar adapun buzzer akan digunakan sebagai notifikasi apabila lahan parkir telah penuh. 


\subsection{Penelitian Terkait}

1. Penelitian Yang dilakukan oleh Rudi, Irwan Dinata dan Rudy Kurniawan. 2017 "Rancang Bangun Prototype Smart Parking Berbasis Arduino dan Pemantauan Melalui Smartphone". Pada penelitian ini system parkir yang dibuat menggunakan Sensor Ultrasonik sebagai inputan ke Mikrokontoller untuk membuka dan menutup palng pintu yang digerakan oleh Motor Servo, dan monitoring dilakukan melalui smarthphone melalui aplikasi Blynk untuk mengetahui slot parkir yang kosong [3].

2. Penelitian yang dilakukan oleh Bambang Tri Wahjo Utomo. 2012 "Rancang Bangun Aplikasi Sistem Parkir Mobil Menggunakan Sensor Infrared di Rumah Sakit Aminah Blitar". System ini digunakan untuk menghitung jumlah kendaraan yang masuk dan keluar pada area parkir. menggukan Sensor Infrared kemudian data ini dikirimkan ke Perangkat Komputer untuk ditampilkan jumlah kendaraan yang masuk pada area parker. [4]

3. Penelitian yang dilakukan oleh Ardianto Pranata, Syaiful Nur Arif dan Yusnidah, 2015, "Perancangan Prototipe Sistem Parkir Cerdas Berbasis Mikrokontroler Atmega8535", System ini bekerja dengan menggunakan RFID yang di tempatkan pada pintu portal Parkir sebagai kode akses masuk, dan sensor infrared sebagai sensor slot parkir yang kososng. [5]

4. Penelitian yang dilakukan oleh, Galih Raditya Pradana, 2015. "Smart Parking Berbasis Arduino Uno" Smart Parking Berbasis Arduino Uno" system ini bekerja dengan cara mendeteksi slot parkir yang kosong menggunakan sensor infrared, data dari sensor akan di proses pada arduino dan kemudian data itu di kirim ke Komputer yang kemudian akan diolah pada aplikasi Desktop Microsoft Visual Basic 6.0 yang akan di tampilkan ke monitor status lahan parkir yang kosong.[6]

5. Penelitian yang dilakuakan oleh oleh Achmad Muhajir Shihabudin dan Safrina Amini. 2016." Sistem Monitoring Tempat Parkir Dengan Sensor Ultrasonik Berbasis Arduino Uno Pada Cibinong City Mall" system ini memanfaatkan sensor ultrasonic untuk mendeteksi kendaraan yang parkir, kemudian data slot parkir yang terisi dikirim pada arduino untuk di tampilkan pada sebuah monitor. [7]

6. Penelitian yang dilakukan oleh, Alimuddin, 2018. "Sistem Parkir Cerdas Berbasis Arduino Mega 2560 Rev3". Sistem parkir cerdas ini menggunakan Arduino Mega 2560 ,sebagai perangkat pemrosesan, lcd dan Led digunakan untuk mengetahui letak lahan parkir yang kosong dan juga sensor ultrasoik untuk menyeleksi kendaraan yang masuk berdasarkan ukurannya.[8]

7. Penelitian yang dilakukan oleh Amin Kianpisheh, Norlia Mustaffa, Pakapan Limtrairut dan Pantea Keikhosrokiani, 2012, "Smart Pakring System (SPS) Architecture Using Ultrasonic Detector". Pada penelitian ini system yang dikembangkan adalah system yang berfungsi untuk memonitoring lahan parkir mobil yang masih kosong menggunakan Ultrasonic Detector dan sebuah Led yang terpasang pada atap gedung parkir, apabila mobil berada tepat dibawah Sensor Ultrasonic maka Led akan secara otomotis berwarna hijau, dan apabila slot parkir itu kosong maka Led akan berwarna hijau. Tentunya hal inni akan membantu pengendara mobil yang akan parkir dapat mengetahui slot parkir mana yang kosong.[9]

8. Penelitian yang dilakukan oleh Miss Neelam Masali dan Prof Manjusha Joshi, 2016,"Indor Parking Guidance System". Sistem yang dibangun ini menggunakan Sensor Ultrasonic yang terpasang pada setiap slot parkir untuk mendetekasi kendaraan yang berada pada slot parkir, data ini akan dikirim dan ditampilkan pada monitor untuk menginformasikan ke pengelola parkir tentang slot parkir mana saja yang kosong menggunakan aplikasi dekstop.[10] 


\section{METODE PENELITIAN}

\subsection{Blok Diagram}

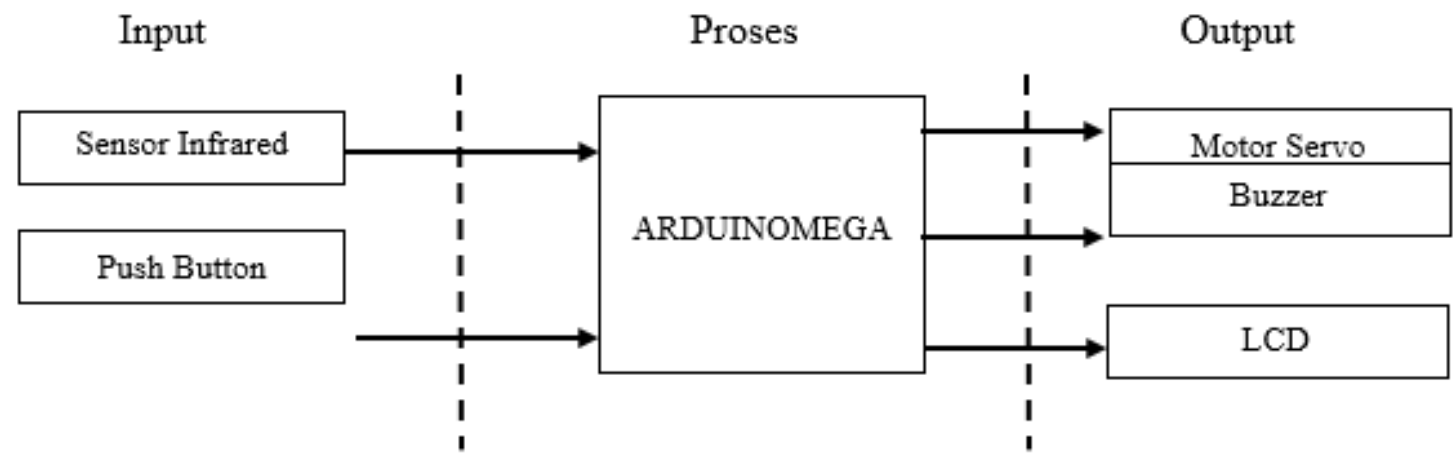

Gambar 3: Blok Diagram

Pada gambar 3 di atas dapat dilihat bahwa Sistema ini menggunakan Microcontoller sebagai perangkat pemrosesan dari inputan yang diterima dari Sensor Infrared maupun Push Button. hasil pemrosesan itu akan dieksekusi perangkat Output yaitu Motor Servo Yang akan Menggerakan Portal dan Buzzer yang akan mengeluarkan bunyi sebagai Notifikasi. Serta LCD menampilkan status lahan Parkir. Semua perangkat tersebut akan dihubungkan seperti pada gambar 4 Skema Rangkaian.

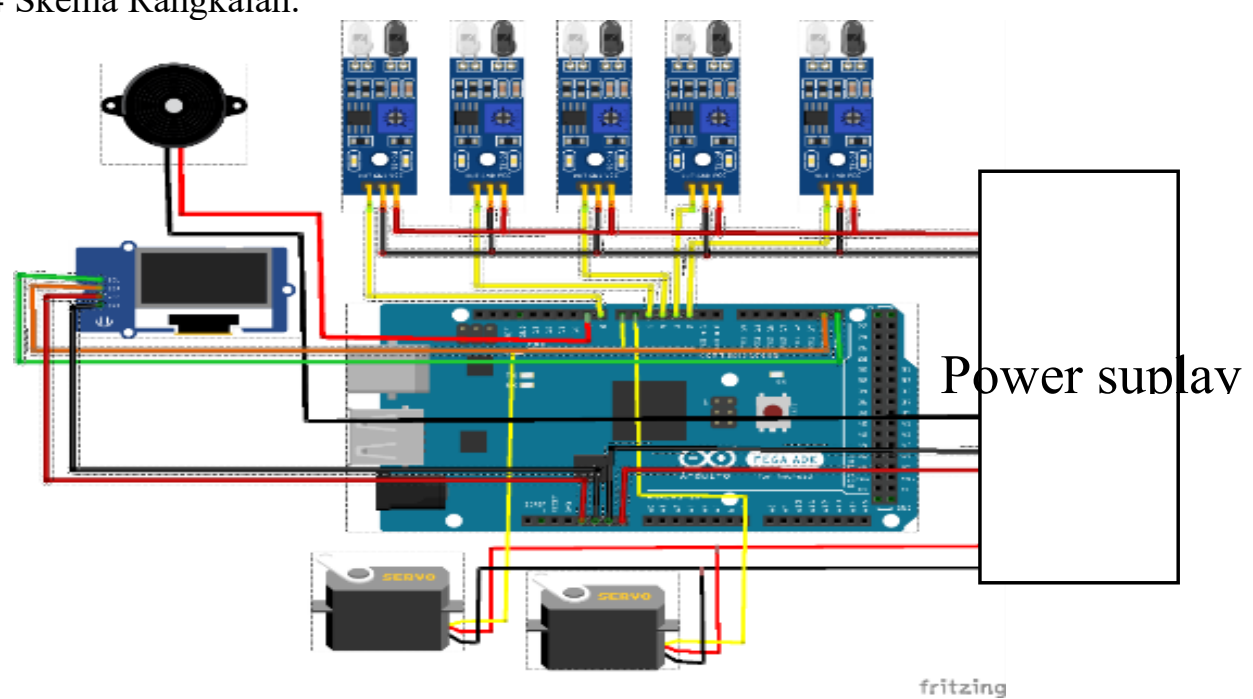

Gambar 4: Skema Ramgkaian

\subsection{Kebutuhan Sistem}

Perangkat yang di perlukan untuk membangun sistem ini seperti pada tabel 1

Tabel 1. Daftar Alat dan Bahan

\begin{tabular}{|l|l|l|}
\hline NO & Nama Alat/Bahan & Jumlah \\
\hline 1 & Arduino Mega 2560 & 1 buah \\
2 & Sensor Infrared & 4 buah \\
3 & Buzer & 1 buah \\
4 & Motor Servo & 2 buah \\
5 & LCD 16 x 2 & 1 buah \\
6 & Software Arduino IDE 1.8.5 & \\
\hline
\end{tabular}




\subsection{Flowchart}

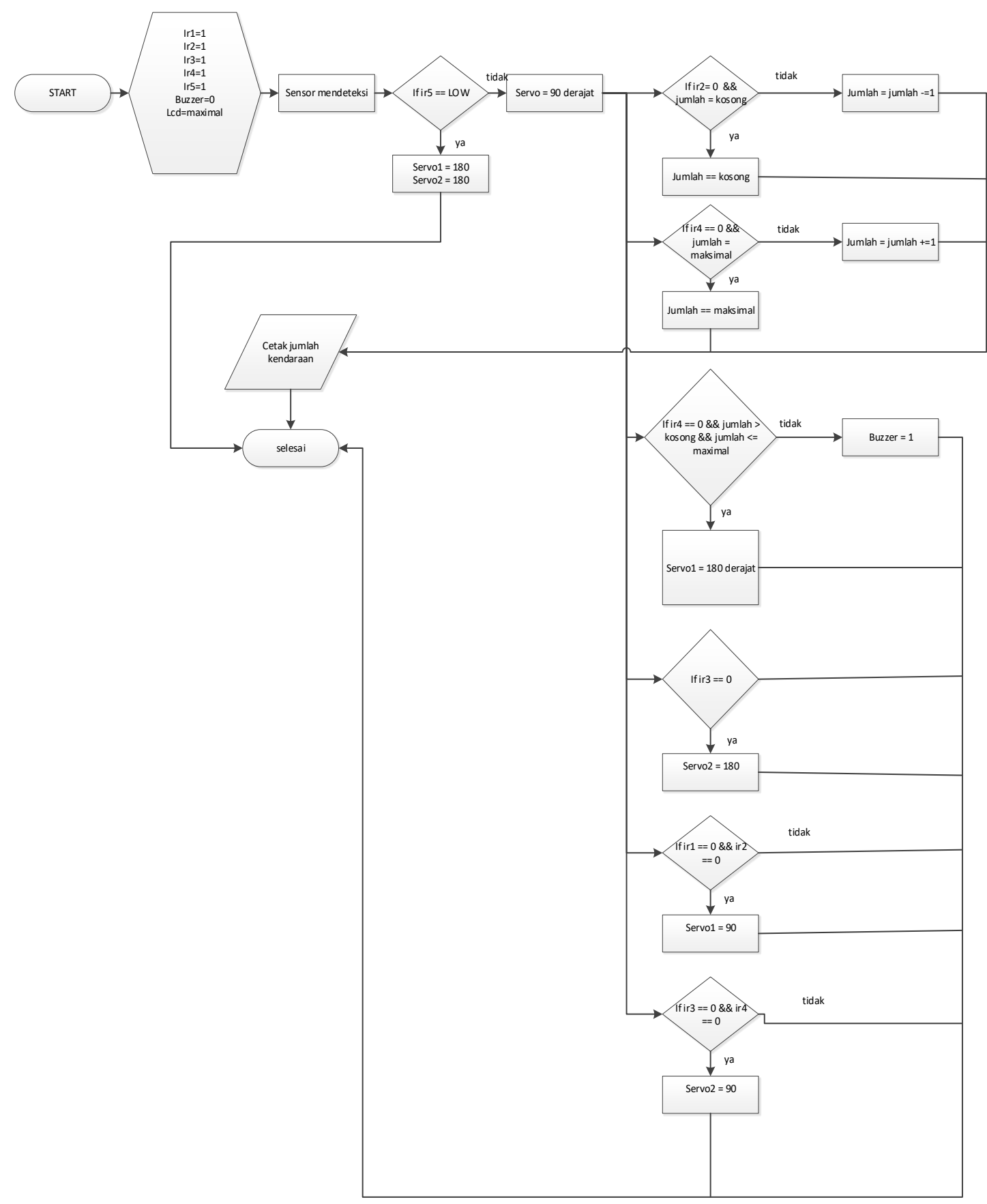

Gambar 5: Flowchart Program

\section{HASIL DAN PEMBAHASAN}

Hasil ini merupakan bentuk Implementasi yang dilakukan dengan menghubungkan semua perankat dengan mikrokontroller dan juga Power Suplay agar dapat berfungsi dengan baik dan juga memasangnya pada sebuah maket berbentuk seprti lahan parkir dengan 2 pintu sebagai pintu masuk dan keluar. 


\subsection{Rangkaian Sensor Infrared}

4 buah Sensor infrared di hubungkan pada Mikrokontroller seperti gambar 6 berikut:

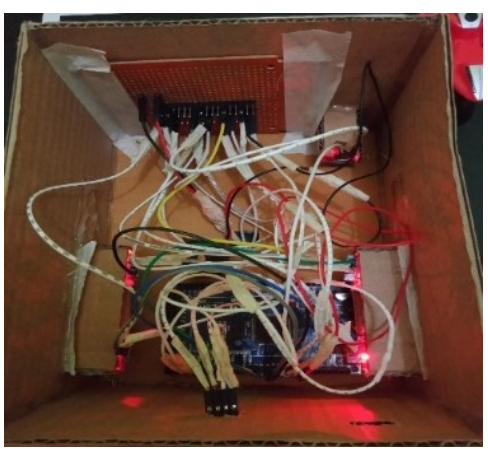

Gambar 6: Rangkaian Sensor Infrared

\subsection{Rangkaian LCD}

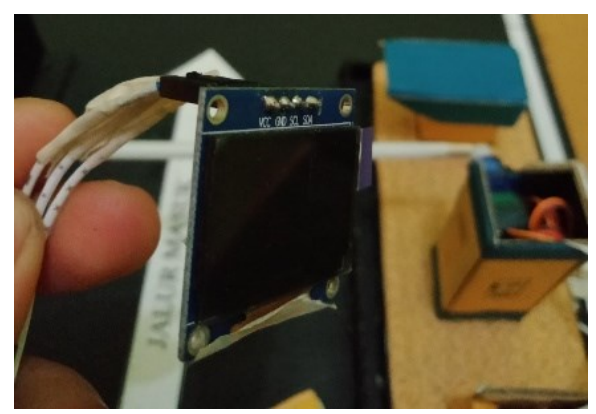

Gambar 7: Rangkaian LCD

\subsection{Rangkaian Buzzer}

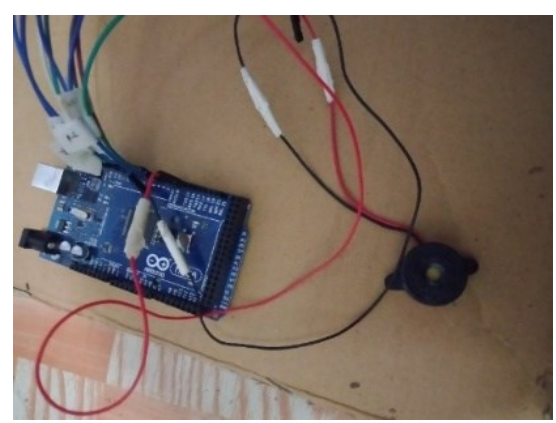

Gambar 8: Rangkaian Buzzer

3.4. Rangkaian Motor Servo

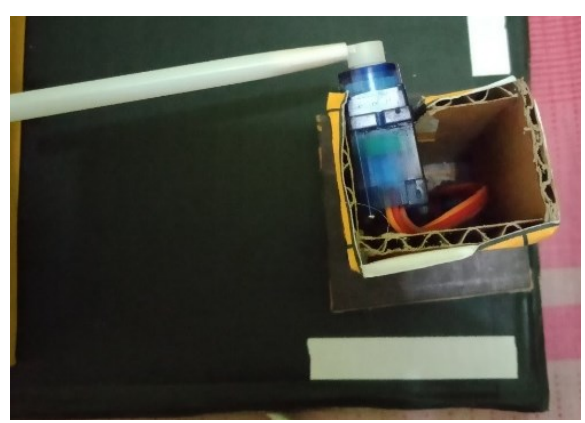




\subsection{Bentuk Maket}

Gambar 8: Rangkaian Motor Servo

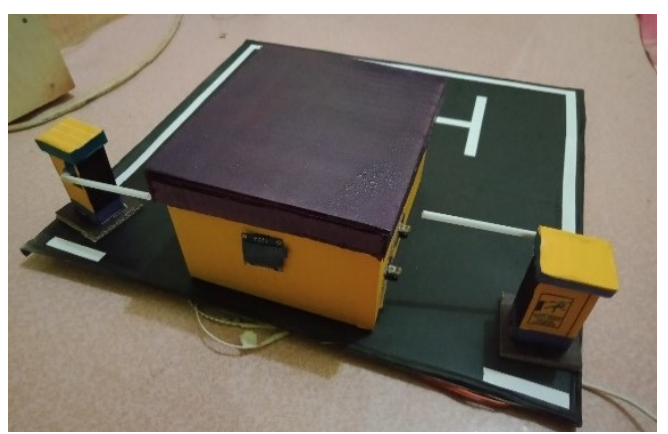

Gambar 9: Bentuk Maket

\subsection{Pengujian}

Pada pengujian sistem ini dilakukan dengan mensimulasikan proses parkir saat kendaraan masuk dan keluar pada lahan parkir yang telah terpasang sensor Infrared dan Portal yang di gerakan Oleh Motor Servo Sg 90.

a. Pengujian 1

Pengujian pertama adalah dengan membiarkan lahan parkir kosong dan hasil dari pengujian pertama adalah LCD mencetak "Slot Tersedia 3" pada pengecekan ini lcd telah mencetak sesuai dengan alur sistem parkir yang dirancang.

b. Pengujian 2

Pengujian kedua dilakukan dengan mensimulasikan kendaraan masuk pada lahan parkir dan hasilnya saat sensor 1 pada pintu masuk mendeteksi Servo1 bergerak 180 derajat dan saat servo 2 mendeteksi LCD mencetak "Slot Tersedia 2" hasil counting dari inputan sensor 2 .

c. Pengujian 3

Pada pengujian ke -3 dilakukan dengan memasukan kendaraan ke 2 masuk kelahan parkir hasilnya Servo pada pintu masuk mengangkat portal parkir kea rah 180 derajat dan lcd mencetak"slot parkir tersedia 1",

d. Pengujian 4

Pada pengujian ke -4 dilakukan dengan memasukan kendaraan ke 3 masuk kelahan parkir hasilnya Servo pada pintu masuk mengangkat portal parkir kea rah 180 derajat dan bergerak kembali ke posisi 90 derajat dan lcd mencetak"Penuh".

e. Pengujian 5

Pengujian ke 5 dilakukan dengan mencba memasukan kendaraan kedalam lahan parkir saat lahan parkir telah penuh hasilnya motor servo tidak mengerakan portal masuk dan buzzer berbunyi saat ada kendaraan terdeteksi oleh sensor 1 .

f. Pengujian 6

Pengujian ke 6 dilakukan dengan mensimulasikan kendaraan keluar dari lahan parkr hasilnya lcd menampilkan hasil counting "Slot tersedia 1" dan motro servo menggerakan portal pada sudut 180 derajat

g. Pengujian 7

Pengujian ke 8 dilakukan dengan mensimulasikan kendaraan keluar dan masuk pada lahan parikir lahan parkr hasilnya dan motro servol dan servo 2 menggerakan portal pada sudut 180 derajat. 


\section{KESIMPULAN}

Kesimpulan harus mengindikasi secara jelas hasil-hasil yang diperoleh, kelebihan dan kekurangannya, serta kemungkinan pengembangan selanjutnya.

1. Sensor infrared berhasil di integrasikan dengan mikrokontroler untuk mendeteksi kendaraan yang akan masuk dan keluar pada lahan parkir dan sebagai inputan untuk menaikan dan menurunkan portal serta inputan untuk mengcounting jumlah kendaraan

2. Motor servo berhasil diintegrasikan dengan mikrokontroler yang digunakan untuk menaikan dan menurunkan portal berdasarkan inputan dari sensor infrared

3. Buzzer berhasil berbunyi saat ada kendaraan yang akan masuk pada saat lahan parkir telah penuh serta Led berhasil menampilkan jumlah slot parkir yang tersisa dan notifikasi penuh apabila lahan parkir telah penuh.

\section{SARAN}

Tentunya penelitian ini masih jauh dari sempurna dan untuk menyempurnakan penelitian ini diperlukan riset dan pengembangan lebih lanjut. Berikut beberapa saran dari peneliti yang dapat disampaikan:

1. Sebaiknya menambahkan kamera untuk mengidentifikasi plat kendaraan yang keluar dsn masuk pada lahan parkir.

2. Selain dapat mencounting motor sebaiknya dalam riset dan pengembangan selanjutnya dapat juga mencounting kendaraan mobil.

\section{UCAPAN TERIMA KASIH}

Syukur tak lupa saya panjatkan kehadirat Allah SWT atas ridohnyalah penelitian ini dapat dilkaukan, kemuadian tak lupa peneliti mengucapkan terimaksih kepada semua pihak yang memberi dukan sehingga penelitian ini dapat diselesaikan, kepada kedua orang tua tentunya dan bapak ibu dosen serta seluruh teman seangkatan.

\section{DAFTAR PUSTAKA}

[1] Ilham effendi ,2018,pengertian dan kelebihan arduino,https://www.it-jurnal.com/pengertiandan-kelebihan-arduino/ diakses tg1 10 Maret 2020

[2] Arfi, Cara Menggunakan Sensor Infrared Proximity Dengan Arduino, https://mechasolution.co.id/cara-menggunakan-sensor-infrared-proximity-dengan-arduino/ diakses Tgl 10 Maret 2020

[3] Rudi, Irwan Dinata, Rudy Kurniawan,2017,' Rancang Bangun Prototype Sistem Smart Parking Berbasis Arduino Dan Pemantauan Melalui Smartphone' Jurnal Ecotipe, Vol.4, No. 2.

[4] Bambang Tri Wahjo Utomo,2017,'Rancang Bangun Aplikasi Sistem Parkir Mobil Menggunakan Sensor Infrared di Rumah Sakit Aminah Blitar'

[5] Ardianto Pranata, Syaiful Nur Arif dan Yusnidah,2015,'Perancangan Prototipe Sistem Parkir Cerdas Berbasis Mikrokontroler Atmega8535'

[6] Decy Nataliana, Iqbal Syamsu, Galih Giantara, 2014, 'Sistem Monitoring Parkir Mobil Menggunakan Sensor Infrared Berbasis RASPBERRY PI',Vol. 2, No. 1 
[7] Shihabudin Achmad Muhajir A.K. Safrina Amini,2016,' Sistem Monitoring tempat Parkir Berbasis Arduino Pada Cibinong City Mall,

[8] Alimuddin,2018'Sistem Parkir Cerdas Berbasis Arduino Mega 2560 Rev3”, Jurnal elektro luceat vol. 4 No. 1

[9] Amin Kianpisheh, Norlia Mustaffa, Pakapan Limtrairut dan Pantea Keikhosrokiani, 2012'Smart Pakring System (SPS) Architecture Using Ultrasonic Detector 'International Journal of Software Engineering and Its Applications Vol. 6, No. 3

[10] Miss Neelam Masali dan Prof Manjusha Joshi, 2016,' Indor Parking Guidance System,.vol. 3 